\title{
Role of Adenosine Deaminase Estimation in Differentiation of Tuberculous and Non-tuberculous Exudative Pleural Effusions
}

\author{
Bharat Kumar Gupta ${ }^{\mathrm{a}, \mathrm{c}}$, Vinay Bharat ${ }^{\mathrm{b}}$, Debapriya Bandyopadhyay ${ }^{\mathrm{a}}$
}

\begin{abstract}
Background: Tuberculosis kills five lakh patients every year in India, commonest being pulmonary tuberculosis and is often associated with effusion. Delay in diagnosis and treatment results in poor prognosis. Several studies have suggested the role of adenosine deaminase (ADA) in the diagnosis of tuberculous pleural effusions, but false-positive results from lymphocytic effusions have also been reported. The purpose of this study is to find out the role of ADA levels in differentiation of tuberculous and non-tuberculous exudative pleural effusions of different etiologies.
\end{abstract}

Methods: Ninety-six lymphocytic pleural fluid samples were consecutively selected and divided into two groups: tuberculous $(\mathrm{n}=$ 56) and non-tuberculous $(n=40)$, depending upon the etiology [Malignancy $(\mathrm{n}=16)$, Infectious diseases $(\mathrm{n}=18)$, Pulmonary embolism $(n=1)$, Collagen vascular diseases $(n=3)$ and Sarcoidosis $(\mathrm{n}=2)]$. ADA was estimated in pleural fluid in all the cases.

Results: In all 56 samples, ADA level of tuberculous group was above diagnostic cut-off (40 U/L), while only one sample was above cut-off in non-tuberculous group $(2.5 \%)$. The negative predictive value of ADA for the diagnosis of non-tuberculous etiology was $97.5 \%$ (39 of 40) lymphocytic pleural effusion patients.

Conclusions: In this study, ADA levels in nontuberculous exudative pleural effusions rarely exceeded the cut-off; set for tuberculous disease. The pleural fluid ADA levels were significantly higher in tuberculous exudative pleural effusions when compared with non-tuberculous exudative pleural effusions.

\footnotetext{
Manuscript accepted for publication March 12, 2010

${ }^{a}$ Department of Biochemistry, Subharti Medical College, S. V. S. Uni versity, Meerut, India

${ }^{\mathrm{b}}$ Department of Pathology, Subharti Medical College, S. V. S. Univer sity, Meerut, India

${ }^{\mathrm{c} C o r r e s p o n d i n g ~ a u t h o r: ~ 69 / 70 ~ N e w ~ M a r k e t, ~ B e g u m ~ B r i d g e, ~}$

Meerut-250001, India. Email: anchitbharat@hotmail.com
}

doi:10.4021/jocmr2010.03.280w
Keywords: Adenosine deaminase; Tuberculous effusion; Pleural fluid; Exudative pleural effusions

\section{Introduction}

Five lakh patients of tuberculosis die every year in India [1], commonest being pulmonary tuberculosis and is often associated with effusion, of which $8.3 \%$ is childhood tuberculosis. Multidrug resistance in tuberculosis and its association with acquired immuno-deficiency syndrome (AIDS) has further highlighted the importance of this disease. Delay in diagnosis and in the start of effective treatment results in poor prognosis and sequalae in upto $25 \%$ of cases [2]. Available methods of diagnosis of tuberculosis were evaluated and all of them were found to have low sensitivity and specificity. Direct evidence of acid fast bacilli (AFB) is available only in small percentage of cases.

Similar difficulties are encountered in cases of tuberculous pleuritis (TP). TP with effusion as a complication of primary pulmonary tuberculosis has been reported to occur in 2 to $38 \%$ of children with pulmonary disease, but it is more likely to occur in adolescents and adults [3-9]. The pleural fluid of TP is usually predominantly lymphocytic. Some studies suggest that pleural fluid lymphocyte percentages of more than $85 \%$ are very suggestive of tuberculosis [10], while the other series of patients with TP indicates that only $10 \%$ patients had less than $50 \%$ lymphocytes in pleural fluid [11]. Acute TP may show an increase in neutrophils [12]. But if a continuous pleural tapping is done, the cell count shows change. Apart from tuberculosis the other causes of lymphocytic pleural effusions include malignancies, infectious diseases, pulmonary embolism, collagen vascular diseases, sarcoidosis, uremia, chylothorax and post-coronary artery bypass graft (CABG) pleural effusion [13].

The classification of pleural effusion into exudative and transudative to support the clinical diagnosis has been well established. There are several causes of exudative pleural effusion including tuberculosis, neoplasms (primary or secondary), pyogenic bacterial infections, fungal infection, sar- 
coidosis, collagen vascular disease, transplant patients with graft rejection, trauma, and pulmonary embolism. Microscopy of fluid shows neutrophillic predominance in bacterial infectious etiology, while in others there is lymphocytic predominance. Presentation of pulmonary embolism can be obscure either as a transudative or an exudative pleural collection.

Usefulness of adenosine deaminase (ADA) estimation in pleural fluid has been shown as a reliable chemical biomarker specially when there is suspicion of tuberculosis in endemic areas. Sometimes the increase is marked in early stages of the disease and in some other conditions with neutrophillic effusions like in parapneumonic and empyema [14]. Researchers have established that ADA level rarely exceeds the cut-off set for tuberculous effusion in non-tuberculous lymphocytic effusions [15].

The purpose of this study is to find out the role of ADA estimation in differentiation of tuberculous and non-tuberculous exudative pleural effusions.

\section{Materials and Methods}

The project was approved by institutional ethical committee. Patients with pleural effusion admitted in the wards of Tuberculosis and chest diseases department from January 08 to November 09 at the Subharti Medical College, Meerut, India were included in the present study. After the routine procedure of informed consent, history taking and examination, routine investigations were done in all the patients.

Presence of first or more than one of the following criteria was adopted to label a case as tuberculous: (1) bacteriological confirmation of presence of Mycobacterium tuberculosis (direct smear or culture or histological finding); (2) histopathology finding of caseating granulomas; (3) radiological findings consistent with TB; (4) clinical presentation consistent with TB with exclusion of other clinical considerations; (5) definite clinical and radiological improvement in two months of administration of exclusive anti-tubercular treatment; (6) history of contact of current disease and positive reaction ( $>20 \mathrm{~mm}$ induration) to the 5 tuberculin unit (TU) purified protein derivative (PPD).

Pleural tap was done in all the cases and fluid tested for $\mathrm{pH}$, glucose, proteins, LDH, total ADA, microscopy, cytology and microbial testing (Grams staining, Z N Staining, cultures). Pleural biopsy was done in selected cases of tuberculosis and malignancy.

All the cases had exudative effusion as per Light's criteria (pleural fluid protein / serum protein > 0.5; fluid LDH / serum LDH > 0.6) [16].

Effusion was called as malignant when pleural fluid cytology or pleural biopsy showed evidence of malignancy or if the patient had proved metastatic malignancy with no other detectable cause of effusion. In infectious disease effu- sion, patient had a history of fever and pulmonary infiltrate with complete response to antibiotic therapy; pulmonary embolism effusion patients presented with typical dyspnoea of sudden onset, leg pains with its signs and symptoms; collagen vascular disease effusion patients had a history of fever and dyspnoea with evidence of eosinophilia and arrhythmia while sarcoidosis effusion patients had multi organ involvement with presence of non-caseating granuloma.

Adenosine deaminase estimation was done by BlakeBerman method [17] which is comparable with the GiustiGalanti method as is established by a meta-analysis of 2251 cases [18]. Adenosine deaminase Level of more than $40 \mathrm{U} / \mathrm{L}$ is taken as cut-off for tuberculosis, same value was taken by other workers also [19].

\section{Statistical analysis}

Results are expressed as Mean \pm SD. The statistical analyses applied included the standard normal variate test, to analyze the difference between tubercular $(n=56)$ and non-tubercu$\operatorname{lar}(\mathrm{n}=40)$ quantitative variable's at $1 \%$ level of significance (Table 4).

\section{Results}

In our study, 96 samples were thus included between the age group of 12 to 76 years. Male : Female ratio is $3: 1$. Tuberculous group had 56 samples while non-tuberculous group had 40 samples. Non-tuberculous group included different etiologies, namely, malignancy $(\mathrm{n}=16)$, infectious diseases $(\mathrm{n}=18)$, pulmonary embolism $(\mathrm{n}=1)$, collagen vascular diseases $($ CVD) $(n=3)$ and sarcoidosis $(n=2)$ (Table 1).

Out of 56 , only 9 cases $(16.07 \%)$ were confirmed as having tuberculosis by bacteriological confirmation of presence of Mycobacterium tuberculosis.

Table 1. Distribution of the Cases According to Accepted Criteria

\begin{tabular}{lll}
\hline Group & Disease & $\begin{array}{l}\text { Number } \\
\text { of Cases }\end{array}$ \\
\hline $\begin{array}{l}\text { Tuberculosis } \\
(\mathrm{n}=56)\end{array}$ & Tuberculosis & 56 \\
$\begin{array}{l}\text { Non-Tuberculosis } \\
(\mathrm{n}=40)\end{array}$ & $\begin{array}{l}\text { Malignancy } \\
\text { Infectious diseases }\end{array}$ & 18 \\
& $\begin{array}{l}\text { Pulmonary embolism } \\
\text { Collagen vascular disease }\end{array}$ & 3 \\
& Sarcoidosis & 2 \\
\hline
\end{tabular}


Table 2. Biochemical Parameters in Pleural Fluid in Different Groups

\begin{tabular}{|c|c|c|c|c|c|}
\hline Group & Disease & pH & Glucose $\mathbf{m g} \%$ & Protein g\% & LDH U/L \\
\hline $\begin{array}{l}\text { Tubercular } \\
(\mathrm{n}=56)\end{array}$ & $\begin{array}{l}\text { Tuberculosis } \\
(\mathrm{n}=56)\end{array}$ & $7.31 \pm 0.09$ & $46.2 \pm 17.6$ & $4.3 \pm 0.9$ & $151.6 \pm 27.0$ \\
\hline \multirow{5}{*}{$\begin{array}{l}\text { Non-Tubercular } \\
(\mathrm{n}=40)\end{array}$} & Malignant $(\mathrm{n}=16)$ & $7.32 \pm 0.07$ & $42.2 \pm 19.6$ & $4.2 \pm 1.1$ & $147.4 \pm 18.6$ \\
\hline & $\begin{array}{l}\text { Infectious diseases } \\
(\mathrm{n}=18)\end{array}$ & $7.31 \pm 0.08$ & $31.4 \pm 17.8$ & $4.1 \pm 1.2$ & $141.7 \pm 23.1$ \\
\hline & $\begin{array}{l}\text { Pulmonary embolism } \\
(\mathrm{n}=1)\end{array}$ & 7.29 & 40.7 & 3.9 & 136.0 \\
\hline & $\begin{array}{l}\text { Collage Vascular Disease } \\
(\mathrm{n}=3)\end{array}$ & $7.27 \pm 0.05$ & $51.5 \pm 14.6$ & $4.4 \pm 0.7$ & $154.6 \pm 13.7$ \\
\hline & $\begin{array}{l}\text { Sarcoidosis } \\
(\mathrm{n}=2)\end{array}$ & $7.32 \pm 0.03$ & $58.8 \pm 18.9$ & $4.2 \pm 0.9$ & $148.6 \pm 11.6$ \\
\hline
\end{tabular}

Mean $\pm \mathrm{SD}$ of $\mathrm{pH}$ in tuberculous group was $7.31 \pm 0.09$, in malignant group it was $7.32 \pm 0.07$, in infectious disease group it was $7.31 \pm 0.08$, in pulmonary embolism it was 7.29 , in CVD group it was $7.27 \pm 0.05$ while in sarcoidosis it was $7.32 \pm 0.03$ (Table 2).

Mean \pm SD of glucose in tuberculous group was 46.2 \pm 17.6 , in malignant group it was $42.2 \pm 19.6$, in infectious disease group it was $31.4 \pm 17.8$, in pulmonary embolism it was 40.7, in CVD group it was $51.5 \pm 14.6$ while in sarcoidosis it was $58.8 \pm 18.9 \mathrm{mg} \%$ (Table 2 ).

Mean \pm SD of protein in tuberculous group was $4.3 \pm$ 0.9 , in malignant group it was $4.2 \pm 1.1$, in infectious disease group it was $4.1 \pm 1.2$, in pulmonary embolism it was 3.9 , in CVD group it was $4.4 \pm 0.7$ while in sarcoidosis it was $4.2 \pm$ 0.9 gm \% (Table 2).
Mean \pm SD of LDH in tuberculous group was $151.6 \pm$ 27.0 , in malignant group it was $147.4 \pm 18.6$, in infectious disease group it was $141.7 \pm 23.1$, in pulmonary embolism it was 136.0, in CVD group it was $154.6 \pm 13.7$ while in sarcoidosis it was $148.6 \pm 11.6 \mathrm{U} / \mathrm{L}$ (Table 2).

In tuberculous group the range of ADA was 115.4 (40.6 - 156.0) and mean \pm SD was $67.34 \pm 22.85$ while collectively in non-tuberculous group it was $33.2(4.8$ - 38.0) and 18.60 \pm 9.12 (Table 3).

Amongst different groups in non-tuberculous disease: in malignant group range of ADA was 26.6 (6.4 - 33.0) and mean \pm SD was $9.08 \pm 9.96$, in infectious disease group its range was $27.2(4.8-32.0)$ and mean $\pm \mathrm{SD}$ was $18 \pm 7.83$, in pulmonary embolism it was 13.58 , in CVD group its range was 5 (10.0 - 15.0) and mean \pm SD was $12 \pm 2.65$, in sarcoid-

Table 3. ADA Range With Mean \pm SD in Different Groups

\begin{tabular}{lllc}
\hline Group & Disease & Range & Mean \pm SD \\
\hline Tubercular $(\mathrm{n}=56)$ & TB $(\mathrm{n}=56)$ & $115.4(40.6-156.0)$ & $67.34 \pm 22.85$ \\
$\begin{array}{l}\text { Non-Tubercular } \\
(\mathrm{n}=40)\end{array}$ & Over all & $33.2(4.8-38.0)$ & $18.60 \pm 9.12$ \\
& Malignant $(\mathrm{n}=16)$ & $26.6(6.4-33.0)$ & $9.08 \pm 9.96$ \\
& Infectious diseases $(\mathrm{n}=18)$ & $27.2(4.8-32.0)$ & -- \\
& Pulmonary embolism $(\mathrm{n}=1)$ & 13.58 & $12 \pm 2.65$ \\
& Collagen Vascular Disease $(\mathrm{n}=3)$ & $5(10.0-5.0)$ & $34 \pm 5.66$ \\
\hline
\end{tabular}


Table 4. Pleural Fluid ADA Levels With Their Significance

\begin{tabular}{|c|c|c|c|c|c|c|}
\hline Group & $\begin{array}{l}\text { Number of } \\
\text { Cases }\end{array}$ & $\begin{array}{l}\text { ADA Levels } \\
\text { in } \mathbf{U} / \mathbf{L}\end{array}$ & $\begin{array}{l}\text { True Positive / } \\
\text { Negative Cases }\end{array}$ & Mean \pm SD & z cal & P-value \\
\hline \multirow[t]{3}{*}{ Tuberculous } & 56 & $>40$ & 56 & $67.34 \pm 22.85$ & & \\
\hline & & $\leq 40$ & 00 & & & \\
\hline & & & & & 14.48 & $0.0007(\mathrm{p}<0.01)^{*}$ \\
\hline \multirow[t]{2}{*}{ Non-tuberculous } & 40 & $>40$ & 01 & $18.60 \pm 9.12$ & & \\
\hline & & $\leq 40$ & 39 & & & \\
\hline Total & 96 & & 96 & & & \\
\hline
\end{tabular}

osis group its range was $8(30.0-38.0)$ and mean \pm SD was $34 \pm 5.66 \mathrm{U} / \mathrm{L}$ (Table 3).

Adenosine deaminase level in all 56 samples of tuberculous group was above diagnostic cut-off ( $40 \mathrm{U} / \mathrm{L})$; while in non-tuberculous group only one sample was above cutoff $(2.5 \%)$. The negative predictive value of ADA for the diagnosis of non-tuberculous etiology was $97.5 \%$ (39 of 40) exudative pleural effusion patients (Table 4).

Adenosine deaminase values were compared between tuberculous and non-tuberculous groups and difference in these values was statistically highly significant. On comparing the ADA values amongst different non-tubercular groups; the difference was not statistically significant (Table $4)$.

\section{Discussion}

Tuberculous pleurisy (TP) is a result of delayed hypersensitivity reaction to the tubercle bacilli. Exudative pleural effusion is manifested by various diseases. The diagnosis based on pleural tap: AFB staining is positive in only 10 to $25 \%$ of the cases, while culture for AFB is positive in less than $25 \%$ of the cases [20]. Perez et al in their study have shown the positivity for tubercle bacilli with smear alone in pleural fluid is $11.1 \%$ [21], with culture it is $33.3 \%$ and with pleural biopsy it increases up to $96.2 \%$. These values differ among different workers $[22,23]$. One third of patients with this condition can have a negative tuberculin skin test [11]. Sensitive techniques like PCR show positive results in about $50 \%$ of cases [24].

In patients with tuberculous exudative pleural effusion, neutrophils predominate in the early stages of the disease, while abundant mononuclear cells is a classical finding later and is believed to be due to the proliferation and differentiation of lymphocytes which release lymphokines, which in turn activate macrophages for an enhanced bactericidal activity $[25,26]$. Even pleural fluid cytology takes a back seat while investigating the cause of an exudative pleural effusion, and is usually just evidence supporting our final diagnosis.

Since the conventional diagnostic tools are incapable of pinpointing the cause, so several bio-markers like ADA, interferon (IFN)- $\gamma$, a variety of tumor markers and cytokines, and C-reactive protein (CRP) have been proposed as alternative noninvasive means of establishing tuberculous etiology in cases of exudative pleural effusion [27].

Adenosine deaminase estimation in pleural fluid has long been taken as a marker for tuberculous pleurisy. Levels above $40 \mathrm{U} / \mathrm{L}$ indicate pleural tuberculosis with sensitivity 81 to $100 \%$ and specificity 83 to $100 \%$ [28-30], while some other workers have observed that this cut-off indicates a still higher sensitivity of $90-100 \%$ and specificity of $89-100 \%$ [29, 31-35]. False positive cases reported could be due to empyema, lymphoma, malignancy, parapneumonic or collagen vascular disease $[29,36]$.

The ADA is an enzyme involved in the purine catabolism. It catalyzes the deamination of adenosine to inosine and of deoxyadenosine to deoxyinosine. Adenosine deaminase is involved in the proliferation and differentiation of lymphocytes, specifically the T-lymphocytes. The T-cells release ADA during the process of activation in the presence of live intracellular pathogens. Thus ADA has been looked upon as a marker of cell mediated immune response and specifically T-cell activation. There are several known isoforms of ADA, which arise from different gene loci [37] out of which ADA1 is found in all cells including lymphocytes and monocytes, while ADA-2 is found exclusively in monocytes [38]. ADA2 isoform is the one raised in tuberculous pleurisy, accounting for almost $88 \%$ of total ADA activity. Rise in ADA-1 activity is more commonly associated with pyogenic bacterial infection of the pleural cavity, contributing to a median $70 \%$ of total ADA activity [34]. However there is no clear advantage of using the ADA-2 over the total ADA activity in clinical practice [25]. The total ADA activity assay is in fact preferred for its rapid turnover and low cost. 
Daniil et al, in their study, concluded that the combination of pleural ADA and CRP levels might be sufficient for discriminating between the different groups of exudative pleural effusion [27]. Jadhav and Bardapurkar concluded that ADA is a useful biochemical marker to evaluate exudative pleural effusions [39].

We have found the pleural fluid ADA levels to be consistently increased and more than the cut-off $(40 \mathrm{U} / \mathrm{L})$ in cases of exudative pleural effusions of tuberculous etiology. In cases with non-tubercular exudative pleural effusion the ADA levels were found to be consistently below the cut-off. The negative predictive value of ADA for the diagnosis of non-tuberculous etiology was $97.5 \%$. Therefore, pleural fluid ADA levels can play a very significant role in differentiating cases of exudative pleural effusion into tuberculous and non-tuberculous.

On the contrary, Rafael concluded that the ADA assay should be considered as a screening test to guide further diagnostic procedures in cases of exudative pleural effusion [40]. While Kataria and Imtiaz concluded that ADA testing can be an integral part of diagnostic workup in lymphocyte rich exudative body fluids both in countries with high and low prevalence of tuberculosis [25].

The sensitivity of the ADA as a serological marker for tuberculous exudative pleural effusion depends on the prevalence of the disease in the population. In western countries where the prevalence of tuberculosis is low, the positive predictive value of the test decreases because of the high false positives, but the negative predictive value remains high. Thus ADA can be used for ruling out suspected cases of tuberculosis and can be a very effective screening test.

India has a high prevalence of tuberculosis and the sensitivity and specificity of this test will be high in this population. Therefore ADA estimation being a simple, low cost, rapid and non-invasive test, should become an integral part of the diagnostic work up of exudative pleural effusions in suspected cases of tuberculosis.

In conclusion, in this study, ADA levels in non-tuberculous exudative pleural effusions rarely exceeded the cutoff; set for tuberculous disease. The pleural fluid ADA levels were significantly higher in tuberculous exudative pleural effusions when compared with non-tuberculous exudative pleural effusions. Adenosine deaminase level of less than 40 $\mathrm{U} / \mathrm{L}$ practically excludes the tubercular etiology in exudative pleural effusion cases and thus may be useful in differentiating tuberculous etiology from others in exudative pleural effusion.

\section{References}

1. Tandon P N, Neurotuberculosis: Clinical aspects. Neurology in Tripica. Chopra J S and Sawhney I.M.S. ed Churchill Livingstone Ltd.;1999.358-89.
2. Gecia-monco J C CNS Tuberculosis. Neurologic clinics. Marra C.M. ed.;1999. 17(4):737-60.

3. Waagner DC. The clinical presentation of tuberculous disease in children. Pediatr Ann 1993;22(10):622-628.

4. McAdams HP, Erasmus J, Winter JA. Radiologic manifestations of pulmonary tuberculosis. Radiol Clin North Am 1995;33(4):655-678.

5. Schaaf HS, Beyers N, Gie RP, Nel ED, Smuts NA, Scott FE, Donald PR, et al. Respiratory tuberculosis in childhood: the diagnostic value of clinical features and special investigations. Pediatr Infect Dis J 1995;14(3):189194.

6. Tournier G. [Tuberculosis in children]. Rev Pneumol Clin 1994;50(5):288-294.

7. Pineda PR, Leung A, Muller NL, Allen EA, Black WA, FitzGerald JM. Intrathoracic paediatric tuberculosis: a report of 202 cases. Tuber Lung Dis 1993;74(4):261266.

8. Agrons GA, Markowitz RI, Kramer SS. Pulmonary tuberculosis in children. Semin Roentgenol 1993;28(2):158172.

9. Merino JM, Carpintero I, Alvarez T, Rodrigo J, Sanchez J, Coello JM. Tuberculous pleural effusion in children. Chest 1999;115(1):26-30.

10. Sahn SA. State of the art. The pleura. Am Rev Respir Dis 1988;138(1):184-234.

11. Berger HW, Mejia E. Tuberculous pleurisy. Chest 1973;63(1):88-92.

12. Antony VB, Sahn SA, Antony AC, Repine JE. Bacillus Calmette-Guerin-stimulated neutrophils release chemotaxins for monocytes in rabbit pleural spaces and in vitro. J Clin Invest 1985;76(4):1514-1521.

13. Light RW, Rogers JT, Cheng D, Rodriguez RM. Large pleural effusions occurring after coronary artery bypass grafting. Cardiovascular Surgery Associates, PC. Ann Intern Med 1999;130(11):891-896.

14. Burgess LJ, Maritz FJ, Le Roux I, Taljaard JJ. Combined use of pleural adenosine deaminase with lymphocyte/ neutrophil ratio. Increased specificity for the diagnosis of tuberculous pleuritis. Chest 1996;109(2):414-419.

15. Lee YC, Rogers JT, Rodriguez RM, Miller KD, Light RW. Adenosine deaminase levels in nontuberculous lymphocytic pleural effusions. Chest 2001;120(2):356361.

16. Light RW, Macgregor MI, Luchsinger PC, Ball WC, Jr. Pleural effusions: the diagnostic separation of transudates and exudates. Ann Intern Med 1972;77(4):507513.

17. Blake J, Berman P. The use of adenosine deaminase assays in the diagnosis of tuberculosis. S Afr Med J 1982;62(1):19-21.

18. Banales JL, Pineda PR, Fitzgerald JM, Rubio H, Selman M, Salazar-Lezama M. Adenosine deaminase in the diagnosis of tuberculous pleural effusions. A re- 
port of 218 patients and review of the literature. Chest 1991;99(2):355-357.

19. Jimenez Castro D, Diaz Nuevo G, Perez-Rodriguez E, Light RW. Diagnostic value of adenosine deaminase in nontuberculous lymphocytic pleural effusions. Eur Respir J 2003;21(2):220-224.

20. Scharer L, McClement JH. Isolation of tubercle bacilli from needle biopsy specimens of parietal pleura. Am Rev Respir Dis 1968;97(3):466-468.

21. Perez-Rodriguez E, Perez Walton IJ, Sanchez Hernandez JJ, Pallares E, Rubi J, Jimenez Castro D, Diaz Nuevo G. ADA1/ADAp ratio in pleural tuberculosis: an excellent diagnostic parameter in pleural fluid. Respir Med 1999;93(11):816-821.

22. Antoniskis D, Amin K, Barnes PF. Pleuritis as a manifestation of reactivation tuberculosis. Am J Med 1990;89(4):447-450.

23. Chan C, Arnold M, Mak T. Clinical and pathological features of tuberculous pleural effusion and its longterm consequences. Respiration. 1987;91:106-9.

24. Shah S, Miller A, Mastellone A, Kim K, Colaninno P, Hochstein L, D’Amato R. Rapid diagnosis of tuberculosis in various biopsy and body fluid specimens by the AMPLICOR Mycobacterium tuberculosis polymerase chain reaction test. Chest 1998;113(5):1190-1194.

25. Kataria YP, Khurshid I. Adenosine deaminase in the diagnosis of tuberculous pleural effusion. Chest 2001;120(2):334-336.

26. Leibowitz S, Kennedy L, Lessof MH. The tuberculin reaction in the pleural cavity and its suppression by antilymphocyte serum. Br J Exp Pathol 1973;54(2):152162.

27. Daniil ZD, Zintzaras E, Kiropoulos T, Papaioannou AI, Koutsokera A, Kastanis A, Gourgoulianis KI. Discrimination of exudative pleural effusions based on multiple biological parameters. Eur Respir J 2007;30(5):957-964.

28. Ribera E, Martinez-Vazquez JM, Ocana I, Ruiz I, Segura RM, Encabo G, Pascual C. [Gamma interferon and adenosine deaminase in pleuritis]. Med Clin (Barc) 1990;94(10):364-367.

29. Valdes L, San Jose E, Alvarez D, Sarandeses A, Pose
A, Chomon B, Alvarez-Dobano JM, et al. Diagnosis of tuberculous pleurisy using the biologic parameters adenosine deaminase, lysozyme, and interferon gamma. Chest 1993;103(2):458-465.

30. Muranishi H, Nakashima M, Hirano H, Saitoh T, Takahashi $\mathrm{H}$, Tanaka K, Miyazaki M, et al. Simultaneous measurements of adenosine deaminase activity and tuberculostearic acid in pleural effusions for the diagnosis of tuberculous pleuritis. Intern Med 1992;31(6):752755.

31. Roth BJ. Searching for tuberculosis in the pleural space. Chest 1999;116(1):3-5.

32. Gilhotra R, Sehgal S, Jindal SK. Pleural biopsy and adenosine deaminase enzyme activity in effusions of different aetiologies. Lung India. 1989;3:122-4.

33. Valdes L, Alvarez D, San Jose E, Penela P, Valle JM, Garcia-Pazos JM, Suarez J, et al. Tuberculous pleurisy: a study of 254 patients. Arch Intern Med 1998;158(18):2017-2021.

34. Ungerer JP, Oosthuizen HM, Retief JH, Bissbort SH. Significance of adenosine deaminase activity and its isoenzymes in tuberculous effusions. Chest 1994;106(1):3337.

35. Burgess LJ, Maritz FJ, Le Roux I, Taljaard JJ. Use of adenosine deaminase as a diagnostic tool for tuberculous pleurisy. Thorax 1995;50(6):672-674.

36. Ocana I, Ribera E, Martinez-Vazquez JM, Ruiz I, Bejarano E, Pigrau C, Pahissa A. Adenosine deaminase activity in rheumatoid pleural effusion. Ann Rheum Dis 1988;47(5):394-397.

37. Hirschhorn R, Ratech H. Isozymes of adenosine deaminase. Isozymes Curr Top Biol Med Res 1980;4(131-157.

38. Ungerer JP, Oosthuizen HM, Bissbort SH, Vermaak WJ. Serum adenosine deaminase: isoenzymes and diagnostic application. Clin Chem 1992;38(7):1322-1326.

39. Jadhav AA, Bardapurkar JS. Diagnostic value of adenosine deaminase to differentiate exudates and transudates. Indian J Physiol Pharmacol 2007;51(2):170-174.

40. Laniado-Laborin R. Adenosine deaminase in the diagnosis of tuberculous pleural effusion: is it really an ideal test? A word of caution. Chest 2005;127(2):417-418. 